\title{
Oncology
}

\section{The Impact of a Tumor Diagnosis on Patients' Attitudes toward Advance Directives}

\author{
Jochen Pfirstinger Daniel Kattner Matthias Edinger \\ Reinhard Andreesen Martin Vogelhuber
}

Department of Hematology and Medical Oncology, University Hospital Regensburg,

Regensburg, Germany

\section{Key Words}

Advance directives · Tumor diagnosis · Patient autonomy

\begin{abstract}
Background: Although advance care planning and the completion of advance directives (ADs) are important tools to avoid unwanted aggressive care once patients have lost their decision-making capacity, only a minority of cancer patients are admitted with completed ADs, and little is known about patients' wishes regarding AD consultations. Methods: For 1 year, every new patient admitted to the hematology/oncology outpatient clinic of the University Hospital Regensburg received a self-administered questionnaire comprising a self-evaluation of $A D$ knowledge and questions about preferences regarding consultation partners and the time of consultation. Disease-related data were collected from medical records. Statistics were calculated with SPSS. Results: Of the 500 questionnaires handed out, 394 (75\%) were evaluable and analyzed. Twenty-eight percent of the participants had completed an AD (living will or health care proxy). Ninety-two percent of the participants without ADs had never received a consultation offer from any professional involved. Only $20 \%$ perceived a clear relation between cancer and AD consultations. More than $50 \%$ of the participants without ADs were in favor of consultations 'now' or 'in a few weeks', while more than $40 \%$ objected to AD consultations. Conclusions: Oncology patients have a large unmet demand for AD consultations. However, a relevant percentage of these patients object to AD consultations. Structured and early AD consultation offers should be made, and early discussions about indications for aggressive treatment should take place.




\section{Oncology}

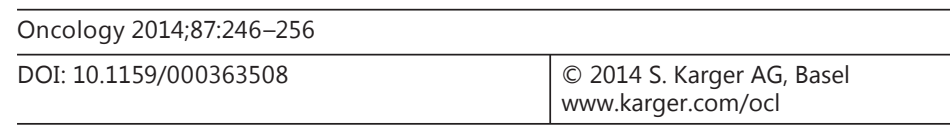

Pfirstinger et al.: The Impact of a Tumor Diagnosis on Patients' Attitudes toward Advance Directives

\section{Introduction}

Respect for a patient's autonomy is considered a fundamental ethical principle, leading to the concepts of shared decision-making and informed consent. In the case of impaired consciousness, particularly in end-of-life situations, patient autonomy is also the ethical basis for the legal instruments of advance care planning. In Germany - as in the USA - there are three types of formal expression of a patient's autonomy [1].

The living will is meant to inform the attending physician about the patient's decisions regarding an end-of-life situation and thereby defines the guidelines for the following treatment such as analgesics, antibiotics, artificial respiration, parenteral nutrition, and cardiopulmonary resuscitation. In addition, the documentation of a health care proxy can be used to designate another person to decide in more complex health care situations. The health care proxy fully represents the will of the patient in case of impaired consciousness regarding health care issues, so that an additional living will is not required but recommended. Furthermore, the durable power of attorney aims at private and financial concerns in incapacitating medical conditions by appointing a person of trust to take care of specific domains. In Germany and many other Western countries, these three elements of advance directives (ADs) are legally binding on medical staff if written down properly and signed by the patient.

In 2009, the revision of a statute concerning ADs in Germany led to a broad public discussion about living wills and resulted in a strict statute strengthening patients' autonomy. Independent of an underlying disease, a written living will is now legally binding with regard to medical decisions if a patient is no longer able to make decisions himself due to illness or incapacity [2].

Preceding surveys showed that $20-40 \%$ of cancer patients report on having a completed $\mathrm{AD}$ (living will and/or durable power of attorney for health care) and that this rate has remained constant over many years [3-6]. It seems to be even lower than $20 \%$ in different European countries independent of the detailed legal situation [7-12]. In cancer patients, early AD consultations are of particular importance due to the imminent risk of impaired consciousness in advanced cases [13-20]. Recent studies showed that ADs improve the process of dying by reducing the patient's fear, the stress on relatives [21], and the physician's risk of burnout [22]. In addition, they might have a positive impact on costs incurred on the health system as well as the patient [23]. These factors lead to the question of how to underline the importance of ADs in the public's perception so that their acceptance will be improved among patients.

It has been shown that, paradoxically, hospitalized cancer patients prefer AD consultations with any admitting physician to an AD consultation with their oncologist [24]. A recent investigation challenged this conclusion and showed that cancer patients would prefer their oncologist if he made 'the first step' toward initiating an AD discussion [4]. These surveys only included hospitalized cancer patients. Hospitalization due to worsening health, complications, or planned intensive therapies marks an ideal time point in the disease course for initiating $\mathrm{AD}$ discussions. Thus far, there have been no comparable surveys in an outpatient setting. Furthermore, little is known about cancer patients' preference [25] regarding when to address advance care planning issues.

This survey was initiated to investigate cancer patients' knowledge about the legal instruments of advance care planning, the patients' preferences regarding AD consultation partners, and the preferred time point for AD consultation after the first diagnosis. 


\section{Oncology}

Table 1. Demographic and disease characteristics of the participants and nonparticipants

\begin{tabular}{l|l}
\hline Oncology 2014;87:246-256 \\
\hline DOI: 10.1159/000363508 & $\begin{array}{l}\text { @ 2014 S. Karger AG, Basel } \\
\text { www.karger.com/ocl }\end{array}$ \\
\hline
\end{tabular}

Pfirstinger et al.: The Impact of a Tumor Diagnosis on Patients' Attitudes toward Advance Directives

\begin{tabular}{lll}
\hline & Participants & Nonparticipants \\
\hline Total number & 394 & 131 \\
Age, years & & \\
$\quad$ Range & $17-86$ & $19-90$ \\
$\quad$ Mean & 57.5 & 59.3 \\
$\quad$ Median & 59.0 & 62.1 \\
$\quad$ Standard deviation & 15.3 & 15.1 \\
Gender, $n$ & & \\
$\quad$ Male & $219(55.6 \%)$ & $72(55.0 \%)$ \\
$\quad$ Female & $175(44.4 \%)$ & $59(45.0 \%)$ \\
Disease, $n$ & & \\
$\quad$ Hematologic neoplasia & $198(50.3 \%)$ & $59(45.0 \%)$ \\
$\quad$ Solid tumor & $131(33.2 \%)$ & $46(35.1 \%)$ \\
$\quad$ Nonmalignant & $65(16.5 \%)$ & $24(17.3 \%)$ \\
$\quad$ Missing & & $2(1.5 \%)$ \\
Disease duration, months & 32 & 29 \\
$\quad$ Mean & 7 & 10 \\
$\quad$ Median & 54 & 42 \\
$\quad$ Standard deviation & & \\
Prognosis, $n$ & $65(16.5 \%)$ & $26(21.0 \%)$ \\
$\quad$ Nonmalignant & $117(29.7 \%)$ & $21(16.9 \%)$ \\
$\quad$ Curative intention & $118(29.9 \%)$ & $33(26.6 \%)$ \\
$\quad$ Palliative $>2$ years & $52(13.2 \%)$ & $26(21.0 \%)$ \\
Palliative 0.5-2 years & $42(10.7 \%)$ & $18(14.5 \%)$ \\
$\quad$ Palliative <6 months & & 7 \\
$\quad$ Missing & & \\
\hline
\end{tabular}

\section{Patients and Methods}

Design

For a period of 1 year, a self-administered questionnaire (online questionnaire 1; for all online suppl. material, see www.karger.com/doi/10.1159/000363508) was handed out to every patient admitted to the hematology/oncology outpatient clinic of the University Hospital Regensburg, excluding patients admitted with coagulation disorders that were not the subject of our survey. The study was approved by the institutional ethics committee.

\section{Patients}

Between August 2009 and July 2010, 500 questionnaires were handed out to 525 consecutive first-time admissions to the hematology/oncology outpatient clinic, and 394 questionnaires $(75 \%)$ were returned and could be analyzed. The patients' characteristics are summarized in table 1.

\section{Data Collection}

We designed a questionnaire comprising a self-evaluation of the patients' knowledge about ADs and questions about their consultation partner in case they had prearranged ADs, about which consultation partner they favored, and about the favored $\mathrm{AD}$ consultation time in relation to the time of the survey as well as in relation to the disease status. Furthermore, a consultation was offered to patients without an AD.

From the medical records of all participants, demographic data and data related to the disease (particularly the time since diagnosis) were collected. Depending on the diagnosis, concomitant diseases, and their general health condition, we separated the patients into five prognosis groups as outlined in the Results section below.

Statistical Analysis

Statistics were performed with SPSS. For the statistical dependence between completed ADs and age, disease duration, and estimated prognosis, Spearman's rank correlation coefficients were calculated. 


\section{Oncology}

\begin{tabular}{l|l}
\hline Oncology 2014;87:246-256 \\
\hline DOI: 10.1159/000363508 & $\begin{array}{l}\text { @ 2014 S. Karger AG, Basel } \\
\text { www.karger.com/ocl }\end{array}$ \\
\hline
\end{tabular}

Pfirstinger et al.: The Impact of a Tumor Diagnosis on Patients' Attitudes toward Advance Directives

Fig. 1. Preferred AD consultation partners of the participants without ADs.

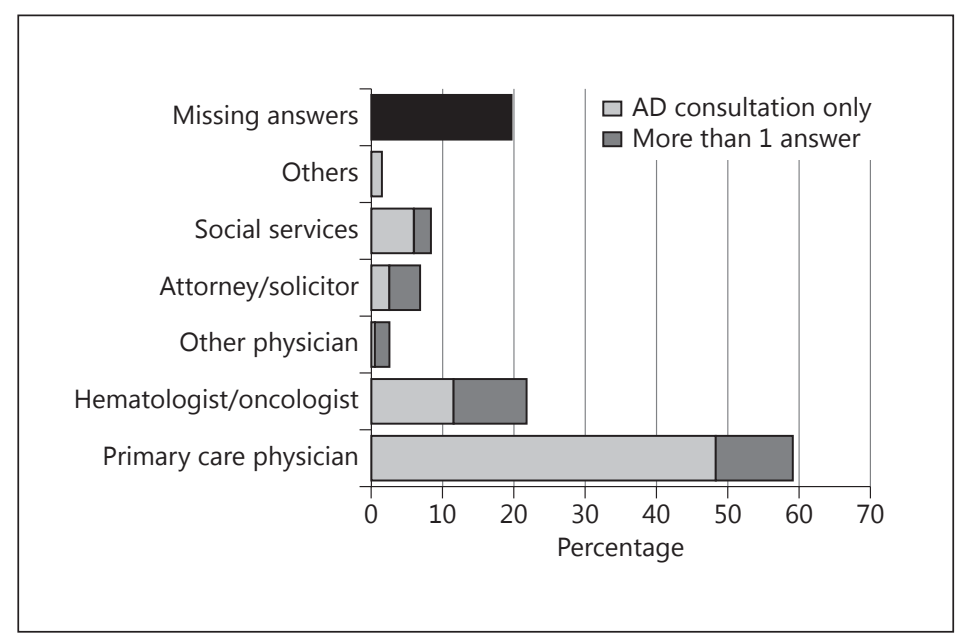

\section{Results}

\section{Participants}

The participants (table 1) had a mean age of 58 years (range: $17-86)$, and $56 \%$ (219/394) were male. A total of $84 \%$ (329/394) had a malignant disease, of whom $60 \%(198 / 329)$ had a hematologic neoplasia and $40 \%(131 / 329)$ had a solid tumor. Patients with nonmalignant disease consulted our outpatient clinic for the examination of cytopenias or other suspected conditions in which no malignant disease could be found or they had a different hematologic nonmalignant disease.

The prognosis groups were separated into the categories 'no malignant disease' and 'curative intention', including patients with complete remission in follow-up care or patients with high-grade lymphoma or acute leukemia under therapy, as well as the 'palliative' category, which was further separated into the three subgroups 'life expectancy $>2$ years', 'life expectancy between 6 months and 2 years', and 'life expectancy $<6$ months' according to the underlying disease, the disease status, and the general health condition.

Patients with indolent lymphoma or plasmacytoma or patients in good condition with solid tumors such as breast or prostate cancer were mostly classified into the life expectancy $>2$ years' subgroup. Most patients with metastatic solid tumors (e.g. lung, stomach, or colon cancer) were classified into the 'between 6 months and 2 years' subgroup. Patients in poor condition with extensive solid tumors or rapidly growing solid tumors, such as malignant melanoma or pancreatic cancer, or with high-grade hematologic malignancies without the option of life-prolonging therapy were classified into the 'life expectancy $<6$ months' subgroup.

\section{Completed ADs and Knowledge about ADs}

In all, 28\% (109/394) of the participants had completed an AD (living will or health care proxy) at the time of our survey; $92 \%(251 / 272)$ of all the patients without ADs who answered this question had never received a consultation offer from a professional involved in their treatment.

\section{AD Consultation Preferences}

Of the 285 participants without completed ADs, 231 (81\%) specified their preferred AD consultation partner: $8 \%(19 / 231)$ wished to have legal advice, of whom $37 \%(7 / 19)$ 


\section{Oncology}

\begin{tabular}{l|l}
\hline Oncology 2014;87:246-256 \\
\hline DOI: $10.1159 / 000363508$ & $\begin{array}{l}\text { (c) 2014 S. Karger AG, Basel } \\
\text { www.karger.com/ocl }\end{array}$ \\
\hline
\end{tabular}

Pfirstinger et al.: The Impact of a Tumor Diagnosis on Patients' Attitudes toward Advance Directives

Fig. 2. Preferred AD consultation in relation to the disease of the participants without completed ADs.

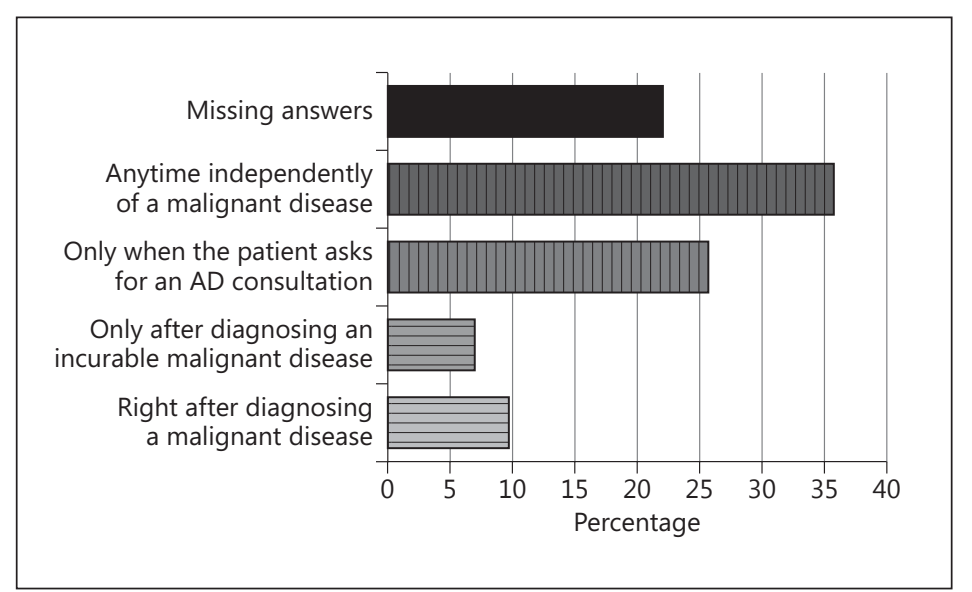

Table 2. Preferred AD consultation in relation to disease severity (number of participants)

\begin{tabular}{|c|c|c|c|c|c|c|}
\hline & \multicolumn{5}{|l|}{ Prognosis } & \multirow[t]{2}{*}{ Total } \\
\hline & $\begin{array}{l}\text { no malignant } \\
\text { disease }\end{array}$ & $\begin{array}{l}\text { curative } \\
\text { intention }\end{array}$ & $\begin{array}{l}\text { palliative } \\
>2 \text { years }\end{array}$ & $\begin{array}{l}\text { palliative } \\
0.5-2 \text { years }\end{array}$ & $\begin{array}{l}\text { palliative } \\
<6 \text { months }\end{array}$ & \\
\hline Independently of a malignant disease & 14 & 35 & 25 & 14 & 11 & 99 \\
\hline Only when the patient asks for an $\mathrm{AD}$ consultation & 15 & 23 & 23 & 3 & 7 & 71 \\
\hline Right after the first diagnosis of a malignant disease & 9 & 7 & 7 & 3 & 1 & 27 \\
\hline $\begin{array}{l}\text { Only after the diagnosis of an incurable malignant } \\
\text { disease }\end{array}$ & 5 & 8 & 3 & 3 & 0 & 19 \\
\hline Total & 43 & 73 & 58 & 23 & 19 & 216 \\
\hline
\end{tabular}

wanted only legal advice and 63\% (12/19) specified more than 1 preferred AD consultation partner; $26 \%(60 / 231)$ chose an $\mathrm{AD}$ consultation with their hematologist/oncologist [53\% (32/60) exclusively; 47\% (28/60) gave more than 1 answer], and 163 participants preferred an AD consultation with their primary care physician, meaning that $71 \%(163 / 231)$ of all the participants who specified a preferred AD consultation partner chose their primary care physician [82\% (133/163) exclusively; 18\% (30/163) gave more than 1 answer; fig. 1].

When asked about the preferred time for an $\mathrm{AD}$ consultation in relation to the disease status (fig. 2), 47\% (135/286) of the respondents commented that consultations about ADs should take place independently of a malignant disease. Another 33\% (93/286) stated that an $\mathrm{AD}$ should only be issued when the patient asks for it; $12 \%(33 / 286)$ declared that an $\mathrm{AD}$ consultation should take place after the first cancer diagnosis, and another $9 \%$ (25/286) of the respondents wished to have an $\mathrm{AD}$ consultation in the case of incurable malignant disease. Even most of the patients within the worst prognosis subgroups with an estimated life expectancy $<2$ years stated that AD consultations should take place independently of a malignant disease (table 2).

A total of 239 of the 285 participants without ADs (84\%) responded to the question about the preferred time for an AD consultation in relation to the time of our survey $(n=259$ due 


\section{Oncology}

Pfirstinger et al.: The Impact of a Tumor Diagnosis on Patients' Attitudes toward Advance Directives

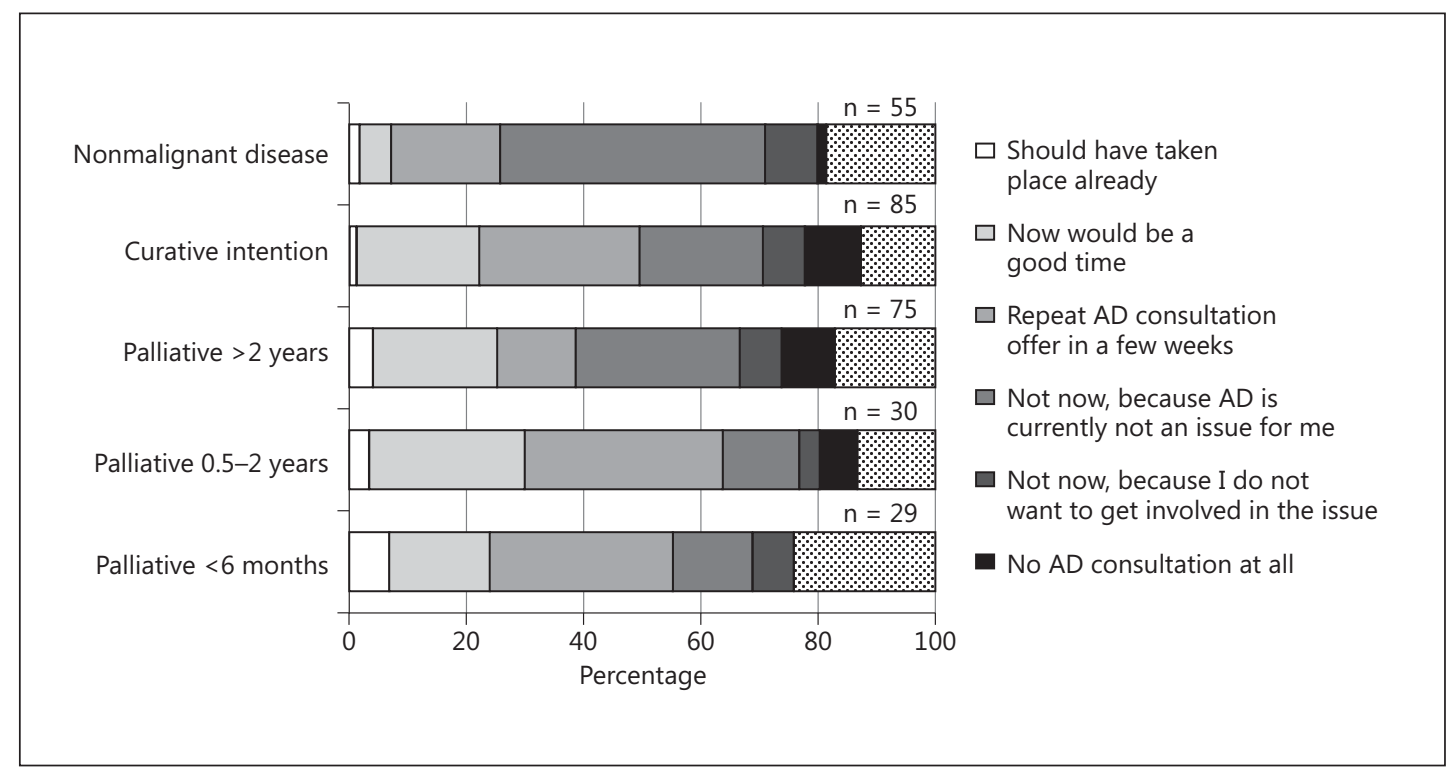

Fig. 3. Preferred AD consultation time in relation to the time of the survey of the participants without completed ADs.

Fig. 4. Preferences for $\mathrm{AD}$ consultations in the near future of the participants without ADs.

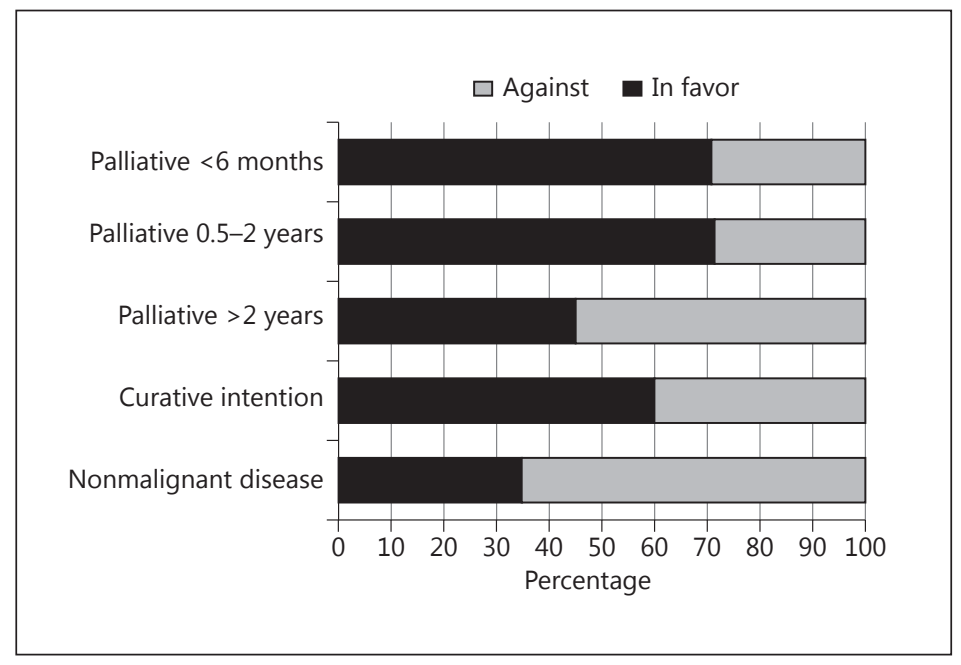

to multiple answers; fig. 3); 5\% (14/259) of the responses expressed that a consultation should have taken place already, 22\% (56/259) stated that 'now' (at the time of the survey) was a good time for an AD consultation, and 26\% (68/259) expressed that a participant wished to receive a consultation offer within the next few weeks. These answers were summarized as participants willing to discuss AD issues in the near future. On the consent document, all participants received an offer for AD consultation with a physician. However, not a single patient made an appointment, even of the participants who answered 'should have already taken place', 'now', or 'in a few weeks'. 


\section{Oncology}

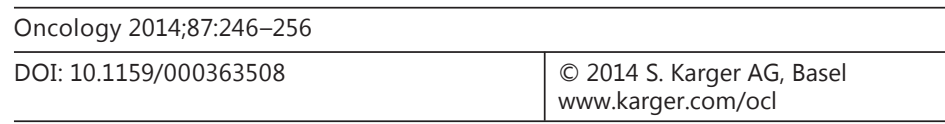

Pfirstinger et al.: The Impact of a Tumor Diagnosis on Patients' Attitudes toward Advance Directives

Fig. 5. Differences in the stated preferences regarding the consultation partner between the participants with and those without completed ADs.

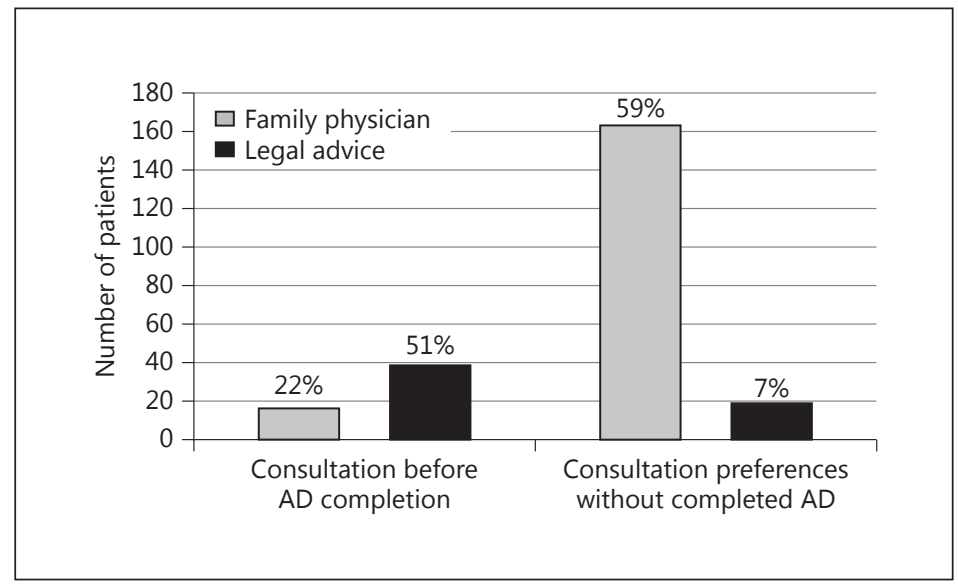

The answers 'not now, because AD is currently not an issue for me' [33\% (79/239) of all the respondents without ADs], 'not now, because I do not want to get involved in the issue' [9\% (22/239)], and 'no AD consultation at all' [8\% (20/239)] were summarized as representing participants not willing to discuss AD issues at the time of the survey or in the near future. There was a larger proportion of these answers from patients with nonmalignant diseases [fig. 4; 65\% (32/49) of the respondents without AD], but even of the patients with malignant diseases, a large fraction [40\% (35/87) in a curative and 44\% (54/123) in a palliative situation] postponed discussions about $\mathrm{AD}$ issues. However, a worsening prognosis resulted in an increased acceptance of AD discussions compared with the patients without malignant diseases or with the patients treated with curative intention (fig. 4). But even of all the 85 patients (regardless of the current AD status) with a very limited prognosis of $<2$ years, $18 \%(15 / 85)$ still postponed written commitments in the context of legal instruments of patient autonomy.

\section{Correlations}

We found a significant correlation between the patients' age and the proportion of completed ADs (Spearman's p: 0.275; significance level: 0.01). Furthermore, a significant correlation between the time since diagnosis and the proportion of completed ADs (Spearman's $\rho$ : 0.185; significance level: 0.01 ) was observed. There was also a positive correlation between poor prognosis and the proportion of completed ADs; however, the prognosis did not seem to be an independent factor as there was a relation between prognosis and disease duration. Nevertheless, we could show an independent correlation between the patients' prognosis and the preferred point of time for a consultation regarding AD issues (Spearman's $\rho$ : -0.186; significance level: 0.01).

\section{Discussion}

In our survey, only $25 \%$ of the participants reported on having a completed living will, whereas $76 \%$ stated that they precisely know, and another $10 \%$ that they approximately know, the meaning and relevance of a living will. This high self-evaluated level of knowledge originates most likely from the public discussion about the revision of a statute concerning ADs in Germany in 2009. The patients seemed to overrate their knowledge, as the awareness 


\section{Oncology}

Pfirstinger et al.: The Impact of a Tumor Diagnosis on Patients' Attitudes toward Advance Directives

of the possibility of assigning a health care proxy, which was not the focus of the public discussion, was much lower.

As reported before [24], our results show as well that patients without ADs prefer a consultation with their primary care physician (71\%) to a consultation with their oncologist (26\%). Although the survey was conducted on patients visiting a university hospital outpatient clinic for the first time, most of them had a cancer history of several months or years and had previously been treated by other oncologists, and still they preferred the primary care physician for discussing AD issues. Surprisingly, more than half of the patients with completed ADs had sought legal advice before (fig. 5), whereas only few patients without completed ADs asked for legal consultation. This indicates that socioeconomic factors or personality traits such as safety needs might play a role in the patients' preferences for AD consultation [26].

Almost half of all the participants who answered this question (nearly equal to the number of participants without completed ADs) stated that AD consultations should take place independently of a cancer diagnosis. Only $20 \%$ of the patients directly linked their interest in $\mathrm{AD}$ consultation to the cancer diagnosis [14]. The willingness to consider one's personal transience seems to increase with age and longer disease duration [27, 28], but a cancer diagnosis alone does not generate an immediate readiness for end-of-life discussions and for the legal instruments of patient autonomy in the case of impaired consciousness [5, 29].

In our cohort, $28 \%$ of the participants without ADs stated that an AD consultation should already have taken place or should take place 'now' at the time of the survey. There obviously is a large unmet need for $\mathrm{AD}$ consultation. Repeated consultation offers seem to be appropriate to reach patients who are uncertain about a potentially negative impact of ADs on optimal cancer treatment or who have other fears [30,31]. Offering structured and repeated $\mathrm{AD}$ consultations to outpatients is more challenging than offering them to hospitalized patients as it requires an appropriate infrastructure and qualified and dedicated personnel. Furthermore, AD consulting often seems to be facilitated by a hospital admission as the reasons for hospitalization, such as upcoming intensive therapy, medical complications, or worsening health condition, can prompt AD discussions [25, 32, 33].

As recently reported, many patients seem to expect the first step toward an AD consultation from the physicians involved [4]. Although our survey was performed in a hematology/ oncology department and included an AD consultation offer in the consent form, the majority of the patients still preferred AD consultations with their primary care physician, in contrast to recent findings [4]. The primary care physician obviously remains the person of trust regarding therapeutic limitations. In the study performed by Dow et al. [4] on inpatients, it was reported that $95 \%$ of the patients considered discussing AD issues at admission 'very or somewhat important'. However, these data were acquired by a physician in an interview setting, which might have led to an overestimation of the patients' readiness for discussing AD issues. In our survey, an anonymous invitation to an AD consultation was offered, requiring the active participation of the patient by making an appointment. Remarkably, none of the patients made an appointment, and almost half of the patients without ADs even objected to the AD consultation offer at the time of the survey ('currently not an issue', 'do not want to get involved in the issue', and 'no AD consultation at all') and did not wish to receive another consultation offer in a few weeks. This was independent of age, the disease duration, and the prognosis. However, in this study, a minority of $5 \%$ of the patients definitely seemed to dismiss AD consultations.

As known from routine clinical practice, there seems to be a group of patients who are not willing to discuss therapeutic limitations or end-of-life matters or decide on treatment options in case of impaired consciousness [1,7-10, 34-37]. The legal instruments of patient 


\section{Oncology}

autonomy fail in these patients. There are no surveys investigating how or whether this group of patients can be reached for AD consultations, but it is very likely that even with optimized communication strategies, not all patients will accept the legal instruments of patient autonomy in the case of impaired consciousness. Thus, a fraction of cancer patients ignores the opportunity to define unwanted medical interventions after losing their decision-making capacity. Not discussing end-of-life matters is also an autonomous decision, but it imposes more responsibility on the physicians involved, as treatment decisions might be required without a statement of the patient about his/her preferences. In medical emergencies, this may easily lead to undesired treatment because maximum therapy is frequently initiated if no limitations have been determined in advance [38].

In palliative care, precautions are usually arranged for threatening emergencies. As in the cancer patient population, these precautions can be communicated to some but not all palliative care patients. In a small group of patients, the complete responsibility for decisions about medical interventions remains with the physicians involved, and decisions about potential interventions in case of emergencies are often made preemptively in team conferences of palliative caretakers. With or without ADs, the medical indication remains the pivotal question and the physicians' responsibility.

Our survey has some limitations. We only investigated the patients' point of view, omitting the physicians' perspective in discussing AD issues. Although we reached a large representative sample, including a diversity of patients with hematologic and nonhematologic as well as malignant and nonmalignant diagnoses in a large urban academic primary care cancer center, not all patients answered all questions, and some questions were only answered by relatively small numbers of patients. Another limitation is the different legal situation in different countries. In Germany, the revision of a statute concerning ADs in 2009 caused a broad public discussion, which might have led not only to more acceptance and increased general knowledge but also to less acceptance and uncertainty due to the public dispute. However, results comparable to those of previous studies indicate that personality traits play a larger role than the detailed legal situation.

Communication strategies for bringing up AD issues in cancer patients should reasonably include the family doctor as the patients' preferred person of trust and the oncologist as the physician with expert knowledge about the natural course of the malignant disease. Further investigations of the group of patients not willing to use the legal instruments of patient autonomy are required. Strengthening the concept of a durable power of attorney for health care may be an option for patients who object to completing a written living will. With patients who also object to a durable power of attorney, an early consideration of medical indications for invasive treatment should take place. Particularly, an early discussion between cancer specialists and family doctors about medical indications in patients with advanced malignant disease and other limiting medical conditions seems necessary to avoid unwanted aggressive care [39].

\section{Disclosure Statement}

The authors declare that they have no conflicts of interest. 


\section{Oncology}

\begin{tabular}{l|l}
\hline Oncology 2014;87:246-256 & $\begin{array}{l}\text { (c) 2014 S. Karger AG, Basel } \\
\text { www.karger.com/ocl }\end{array}$ \\
\hline DOI: 10.1159/000363508 &
\end{tabular}

Pfirstinger et al.: The Impact of a Tumor Diagnosis on Patients' Attitudes toward Advance Directives

\section{References}

1 Angelos P, Kapadia MR: Physicians and cancer patients: communication and advance directives. Cancer Treat Res 2008;140:13-28.

-2 Wiesing U, Jox RJ, Hessler HJ, Borasio GD: A new law on advance directives in Germany. J Med Ethics 2010;36: 779-783.

3 Teno JM: Advance directives: time to move on. Ann Intern Med 2004;141:159-160.

1 Dow LA, Matsuyama RK, Ramakrishnan V, Kuhn L, Lamont EB, Lyckholm L, Smith TJ: Paradoxes in advance care planning: the complex relationship of oncology patients, their physicians, and advance medical directives. J Clin Oncol 2010;28:299-304.

5 Curtis JR: Communicating with patients and their families about advance care planning and end-of-life care. Respir Care 2000;45:1385-1394.

6 Phipps E, True G, Harris D, Chong U, Tester W, Chavin SI, Braitman LE: Approaching the end of life: attitudes, preferences, and behaviors of African-American and white patients and their family caregivers. J Clin Oncol 2003;21:549-554.

7 Sahm S, Will R, Hommel G: What are cancer patients' preferences about treatment at the end of life, and who should start talking about it? A comparison with healthy people and medical staff. Support Care Cancer 2005; 13:206-214.

8 Sahm S, Will R, Hommel G: Attitudes towards and barriers to writing advance directives amongst cancer patients, healthy controls, and medical staff. J Med Ethics 2005;31:437-440.

-9 Sahm S, Will R, Hommel G: Would they follow what has been laid down? Cancer patients' and healthy controls' views on adherence to advance directives compared to medical staff. Med Health Care Philos 2005;8:297-305.

10 Kierner KA, Hladschik-Kermer B, Gartner V, Watzke HH: Attitudes of patients with malignancies towards completion of advance directives. Support Care Cancer 2010;18:367-372.

11 Lang FR, Wagner GG: Patient living wills in Germany: conditions for their increase and reasons for refusal. Dtsch Med Wochenschr 2007;132:2558-2562.

12 Rurup ML, Onwuteaka-Philipsen BD, van der Heide A, van der Wal G, Deeg DJ: Frequency and determinants of advance directives concerning end-of-life care in the Netherlands. Soc Sci Med 2006;62:1552-1563.

13 Bakitas M, Ahles TA, Skalla K, Brokaw FC, Byock I, Hanscom B, Lyons KD, Hegel MT; ENABLE Project Team: Proxy perspectives regarding end-of-life care for persons with cancer. Cancer 2008;112:1854-1861.

14 Berry SR, Singer PA: The cancer specific advance directive. Cancer 1998;82:1570-1577.

15 Bradley NM, Sinclair E, Danjoux C, Barnes EA, Tsao MN, Farhadian M, Yee A, Chow E: The do-not-resuscitate order: incidence of documentation in the medical records of cancer patients referred for palliative radiotherapy. Curr Oncol 2006;13:47-54.

16 Ganti AK, Lee SJ, Vose JM, Devetten MP, Bociek RG, Armitage JO, Bierman PJ, Maness LJ, Reed EC, Loberiza FR Jr: Outcomes after hematopoietic stem-cell transplantation for hematologic malignancies in patients with or without advance care planning. J Clin Oncol 2007;25:5643-5648.

17 McCarthy EP, Phillips RS, Zhong Z, Drews RE, Lynn J: Dying with cancer: patients' function, symptoms, and care preferences as death approaches. J Am Geriatr Soc 2000;48(suppl 5):110-121.

-18 Morita T, Tei Y, Inoue S: Impaired communication capacity and agitated delirium in the final week of terminally ill cancer patients: prevalence and identification of research focus. J Pain Symptom Manage 2003;26: 827-834.

19 Saraiya B, Bodnar-Deren S, Leventhal E, Leventhal H: End-of-life planning and its relevance for patients' and oncologists' decisions in choosing cancer therapy. Cancer 2008;113(12 suppl):3540-3547.

20 Yabroff KR, Mandelblatt JS, Ingham J: The quality of medical care at the end-of-life in the USA: existing barriers and examples of process and outcome measures. Palliat Med 2004;18:202-216.

21 Detering KM, Hancock AD, Reade MC, Silvester W: The impact of advance care planning on end of life care in elderly patients: randomised controlled trial. BMJ 2010;340:c1345.

22 Jackson VA, Mack J, Matsuyama R, Lakoma MD, Sullivan AM, Arnold RM, Weeks JC, Block SD: A qualitative study of oncologists' approaches to end-of-life care. J Palliat Med 2008;11:893-906.

23 Kirk TW, Luck GR: Dying tax free: the modern advance directive and patients' financial values. J Pain Symptom Manage 2010;39:605-609.

24 Lamont EB, Siegler M: Paradoxes in cancer patients' advance care planning. J Palliat Med 2000;3:27-35.

25 Johnston SC, Pfeifer MP, McNutt R: The discussion about advance directives: patient and physician opinions regarding when and how it should be conducted - End of Life Study Group. Arch Intern Med 1995;155:10251030.

26 Becker M, Jaspers B, King C, Radbruch L, Voltz R, Nauck F: Did you seek assistance for writing your advance directive? A qualitative study. Wien Klin Wochenschr 2010;122(21-22):620-625.

27 Joffe S, Mello MM, Cook EF, Lee SJ: Advance care planning in patients undergoing hematopoietic cell transplantation. Biol Blood Marrow Transplant 2007;13:65-73.

28 Kish SK, Martin CG, Price KJ: Advance directives in critically ill cancer patients. Crit Care Nurs Clin North Am 2000;12:373-383.

29 Collins LG, Parks SM, Winter L: The state of advance care planning: one decade after SUPPORT. Am J Hosp Palliat Care 2006;23:378-384. 


\section{Oncology}

\begin{tabular}{l|l}
\hline Oncology 2014;87:246-256 \\
\hline DOI: $10.1159 / 000363508$ & $\begin{array}{l}\text { ○ 2014 S. Karger AG, Basel } \\
\text { www.karger.com/ocl }\end{array}$ \\
\hline
\end{tabular}

Pfirstinger et al.: The Impact of a Tumor Diagnosis on Patients' Attitudes toward Advance Directives

-30 Aitken PV Jr: Incorporating advance care planning into family practice. Am Fam Physician 1999;59:605-614, 617-620.

-31 Ramsaroop SD, Reid MC, Adelman RD: Completing an advance directive in the primary care setting: what do we need for success? J Am Geriatr Soc 2007;55:277-283.

-32 Kass-Bartelmes BL, Hughes R: Advance care planning: preferences for care at the end of life. J Pain Palliat Care Pharmacother 2004;18:87-109.

33 Pentz RD, Lenzi R, Holmes F, Khan MM, Verschraegen C: Discussion of the do-not-resuscitate order: a pilot study of perceptions of patients with refractory cancer. Support Care Cancer 2002;10:573-578.

-34 Reuben DB, Naeim A: Perspectives, preferences, care practices, and outcomes in late-stage cancer patients: connecting the dots. J Clin Oncol 2004;22:4869-4871.

-35 Ditto PH, Hawkins NA: Advance directives and cancer decision making near the end of life. Health Psychol 2005;24(4 suppl):S63-S70.

-36 Pautex S, Herrmann FR, Zulian GB: Role of advance directives in palliative care units: a prospective study. Palliat Med 2008;22:835-841.

-37 Walling A, Lorenz KA, Dy SM, Naeim A, Sanati H, Asch SM, Wenger NS: Evidence-based recommendations for information and care planning in cancer care. J Clin Oncol 2008;26:3896-3902.

38 Kish Wallace S, Martin CG, Shaw AD, Price KJ: Influence of an advance directive on the initiation of life support technology in critically ill cancer patients. Crit Care Med 2001;29:2294-2298.

-39 Levin TT, Li Y, Weiner JS, Lewis F, Bartell A, Piercy J, Kissane DW: How do-not-resuscitate orders are utilized in cancer patients: timing relative to death and communication-training implications. Palliat Support Care 2008; 6:341-348. 